\title{
Microscopic Studies of Various Sizes of Gold Nanoparticles and Their Cellular Localizations
}

\author{
Cemil Boyoglu, ${ }^{1}$ Qingwen He, ${ }^{2}$ Gerold Willing, ${ }^{2}$ Seyhan Boyoglu-Barnum, ${ }^{1}$ \\ Vida A. Dennis, ${ }^{1}$ Shreekumar Pillai, ${ }^{1}$ and Shree R. Singh ${ }^{1}$ \\ ${ }^{1}$ Center for NanoBiotechnology Research, Alabama State University, 1627 Hall Street, Montgomery, AL 36101, USA \\ ${ }^{2}$ Department of Chemical Engineering, University of Louisville, Louisville, KY 40292, USA
}

Correspondence should be addressed to Shree R. Singh; ssingh@alasu.edu

Received 21 May 2013; Accepted 30 June 2013

Academic Editors: D. R. Chen, B. Coasne, D. Galvão, S. Kundu, D. K. Sarker, D. Tsoukalas, and D. K. Yi

Copyright (C) 2013 Cemil Boyoglu et al. This is an open access article distributed under the Creative Commons Attribution License, which permits unrestricted use, distribution, and reproduction in any medium, provided the original work is properly cited.

\begin{abstract}
Gold nanoparticles (GNPs) are widely used in biological and clinical applications due to their favorable chemical and optical properties. GNPs can be used for drug delivery to targeted cells. In addition, GNPs serve as ideal probes for biological and cell imaging applications. Recent studies indicate that the size diversity of GNPs plays an important role in targeting cellular components for biomedical applications. In this study, we conducted a series of studies using different sizes of gold nanoparticles, including 3,10 , 25 , and $50 \mathrm{~nm}$, to determine the effect of size variations on their intracellular localizations. Our cytotoxicity studies of GNPs into the HEp-2 cells using MTT assay indicated that $3 \mathrm{~nm}$ GNPs possess the highest toxicity. We exposed HEp- 2 cells with various sizes of gold nanoparticles for different time intervals $(1,2,4,12$, and $24 \mathrm{~h}$ ) followed by imaging using scanning electron microscope (SEM) and atomic force microscope (AFM). Our SEM and AFM results showed that, after 1 hr incubation, 3 and 10 nm gold nanoparticles entered the nucleus, whereas 25 and $50 \mathrm{~nm}$ particles accumulated around the nucleus. As the time of exposure increased, GNPs entered the cells and accumulated in the cytosol and nucleus based solely on their sizes.
\end{abstract}

\section{Introduction}

Metal nanoparticles are currently used for a variety of biomedical applications [1-4]. The nanoscale size makes them comparable to the cellular components and proteins hence, nanoparticles can easily bypass natural barriers [5]. Metal nanoparticles exhibit remarkable optic, electronic, and chemical properties that can be tailored by size variations $[6,7]$. Recent studies showed that the size diversity of nanoparticles plays a significant role in their extracellular and intracellular mechanisms $[1,8-10]$.

GNPs have been actively investigated in a wide variety of biomedical applications for several reasons; they have the advantage of small size, which is highly tunable $(1-100 \mathrm{~nm})$, they are capable of evading the immune system, and they are easily characterized by UV-Vis spectrometries and microscopies $[11,12]$. The optical properties of GNPs, such as surface plasmon resonance, provide excellent florescence and photostability necessary for imaging applications $[13,14]$. The chemical properties of GNPs, such as chemical inertness, low toxicity to human cells [15], and high selectivity [16], allow them to interact easily with biological systems.

Recent studies of GNPs and their abilities to enter cellular compartments have opened doors for many other biomedical applications beyond GNPs as labels for microscopy use [16]. The GNPs in various cellular organelles provide a unique opportunity to selectively treat diseases and use GNPs as therapeutic agents. The GNPs can be tailor made in various sizes that exhibit various properties. Four different sizes of GNPs $(10,50,100$, and $250 \mathrm{~nm}$ in diameter) tested in animals showed accumulation of $10 \mathrm{~nm}$ GNPs in the blood, liver, spleen, kidney, testis, thymus, lung, and brain, whereas other GNPs accumulated only in the blood, liver, and spleen [17]. Similarly, three sizes of PEG-coated GNPs $(4,13$, and $100 \mathrm{~nm}$ ) administered in animals aggregated in different organs dependent on GNPs sizes [8]. The understanding of the intracellular uptake of GNPs is needed for drug delivery, anti-cancer, and other therapeutic applications $[9$, 18]. Although the cellular localization of nanoparticles has promising potential for applications in cancer treatment, 
drug/gene delivery, diagnosis, and sensing [19, 20], limited studies have been conducted to understand the cellular uptake of different sizes of gold nanoparticles (GNPs) using scanning electron microscope (SEM) and atomic force microscope (AFM), particularly those GNPs without any modifications.

In our study, we used four different sizes $(3,10,25$, and $50 \mathrm{~nm}$ ) of gold nanoparticles (GNPs) in order to determine the effect of size variations in trafficking of GNPs into the HEp-2 cells at various exposure times. Additionally, toxicity of GNPs in the HEp-2 cells was measured using MTT assay. The HEp-2 cells were exposed to GNPs for different time intervals $(1,2,4,12$, and $24 \mathrm{hr})$ and were subsequently imaged using both SEM and AFM. The MTT toxicity studies showed that the $3 \mathrm{~nm}$ GNPs exhibited the maximum toxicity in HEp-2 cells. Our SEM and AFM results showed that $3 \mathrm{~nm}$ and $10 \mathrm{~nm}$ GNPs entered both the cytoplasm and nucleus, whereas $25 \mathrm{~nm}$ and $50 \mathrm{~nm}$ nanoparticles surrounded the nucleus and were mostly localized in the cytoplasm. These studies indicate that GNPs smaller than $10 \mathrm{~nm}$ can be used for nuclear targeting, while GNPs between $10 \mathrm{~nm}$ and $50 \mathrm{~nm}$ are good targets for the cytoplasm.

\section{Experimental Details}

2.1. Gold Nanoparticles. Four different sizes (3, 10, 25, and $50 \mathrm{~nm}$ ) of gold nanoparticles (GNPs) were purchased from Nanopartz, Inc. (Loveland, CO, USA). These GNPs were $<95 \%$ pure with a density of $0.041-0.065 \mathrm{~g} / \mathrm{cm}^{3}$. The sizes of GNPs used in this study were confirmed by DLS characterization.

2.2. Cells. HEp-2 cells were obtained from the American Type Culture Collection (ATCC, Manassas, VA, USA). The cells were cultured in T-75 flasks using minimum essential medium (MEM) supplemented with 1\% L-glutamine, 10\% fetal bovine serum (FBS), and $1 \%$ penicillin-kanamycinstreptomycin antibiotics (PKS). Prior to cell expansion and plating and for other experiments, cells were washed with Hank's balanced salt solution (HBSS). Cytotoxicity experiments were performed on cells plated in 6-well plates, while SEM and AFM were performed in 12 -well plates. Fresh $1 \%$ trypsin was used to trypsinize cells from T-75 flasks. To perform cell counts, a Beckman Coulter Z1 Particle Counter (Fullerton, CA, USA) was used, and $1.2 \times 10^{5} \mathrm{HEp}-2$ cells were plated into each well in $1 \mathrm{~mL}$ MEM for 12 -well plates, $0.6 \times 10^{5}$ HEp-2 cells for 6 -well plates; $2.7 \times 10^{4}$ cells for 8 -chamber slides were plated into each chamber in $250 \mu \mathrm{L}$ MEM.

2.3. MTT Cytotoxicity Assay. The cytotoxicity of GNPs was determined using the MTT assay in HEp-2 cells. Cells were seeded in a 96-well plate at a density of $2.0 \times 10^{4}$ cells/well and incubated overnight at $37^{\circ} \mathrm{C}$. Then, the cells were incubated in $100 \mu \mathrm{L} 10 \%$ FBS containing the selected medium supplemented with $0.5,1,5,10,25$, and $50 \mu \mathrm{g} / \mathrm{mL}$ of GNPs. After $24 \mathrm{hr}$, the medium was removed, and the cells were rinsed twice with sterile PBS. Next, $20 \mu \mathrm{L}$ of MTT solution $(5 \mathrm{mg} / \mathrm{mL})$ in endothelial basal medium (EBM)-phenol red
TABLE 1: Characteristics of gold nanoparticles.

\begin{tabular}{lcccc}
\hline GNPs & $\begin{array}{c}\text { UV-Vis } \\
\mathrm{nm}\end{array}$ & $\begin{array}{c}\text { DLS } \\
\mathrm{nm}\end{array}$ & $\begin{array}{c}\text { Zeta potential } \\
\mathrm{mV}\end{array}$ & $\begin{array}{c}\text { Concentration } \\
\mathrm{nps} / \mathrm{mL}\end{array}$ \\
\hline $3 \mathrm{~nm}$ & 516 & 3 & -38.2 & $2.49 E+14$ \\
$10 \mathrm{~nm}$ & 518 & 10 & -49 & $5.35 E+12$ \\
$25 \mathrm{~nm}$ & 520 & 26 & -34 & $2.56 E+11$ \\
$50 \mathrm{~nm}$ & 531 & 50 & -40 & $4.93 E+10$ \\
\hline
\end{tabular}

free $(100 \mu \mathrm{L})$ was added into each well and allowed to react for $4 \mathrm{hr}$ at $37^{\circ} \mathrm{C}$. Absorbance was measured at $490 \mathrm{~nm}$ using an ELISA plate reader (TECAN US, Inc., Durham, NC, USA).

2.4. Transmission and Scanning Electron Microscopes (TEM, SEM) Analyses. TEM analyses of gold nanoparticles were performed by Nanopartz, and the images were provided along with nanoparticle analyses. HEp-2 cells were grown in a 12 -chamber slide for $48 \mathrm{hr}$, and the desired concentrations of gold nanoparticles were added to each chamber and incubated for different time intervals $(1,2,4,12$, and $24 \mathrm{hr}$ ). This was followed by fixing cells with $200 \mu \mathrm{L}$ methanol for 15 minutes and $200 \mu \mathrm{L}$ distilled water for 15 minutes, wash then successively with $70 \%, 90 \%$, and absolute alcohol for $5 \mathrm{~min}$ each. Following fixation and dehydration, coverslips containing HEp-2 cells were coated with gold using an EMS850 sputter-coating device (Electron Microscopy Sciences, Hatfield, PA, USA). The intracellular uptake of the gold nanoparticles into the HEp-2 cells was then characterized by scanning electron microscopy using a Zeiss EVO 50 VPSEM (Peabody, MA, USA) at Auburn University, Auburn, AL, USA. Images were captured, and changes in the cell morphology measurements were taken using SEMSmart software.

2.5. Atomic Force Microscopy (AFM) Analysis. AFM samples were prepared using the same method previously discussed for SEM. AFM images were obtained using the XE-100 atomic force microscope (Park Systems, Santa Clara, CA) at the University of Louisville (Louisville, KY, USA). HEp-2 cells exposed to GNPs were placed onto a slide, dried, and visualized under the microscope. Noncontact mode and standard silicon cantilevers (Pacific Nanotechnology, Santa Clara, CA, USA) $450 \mu \mathrm{m}$ in length and $20 \mu \mathrm{m}$ in width were employed for imaging. The cantilever oscillation frequency was tuned to the resonance frequency of approximately $256 \mathrm{kHz}$. The setpoint voltage was adjusted for optimum image quality. Both height information, and phase information were recorded at a scan rate of $1 \mathrm{~Hz}$, and in $512 \times 512$ pixel format.

\section{Results and Discussion}

3.1. Characterization of GNPs. Analysis of UV-Visible absorbance spectra revealed the peak for 3, 10, 25, and $50 \mathrm{~nm}$ GNPs at 516, 518, 520, and $531 \mathrm{~nm}$, respectively (Table 1 ). These spectra were within the UV-Vis range for each size of GNPs. The dynamic light scattering (DLS), a measurement of nanoparticle diameter sizes, was consistent for all of 


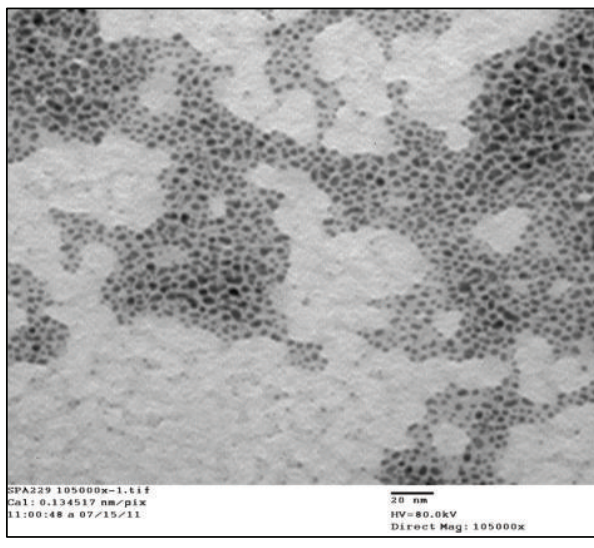

(a)

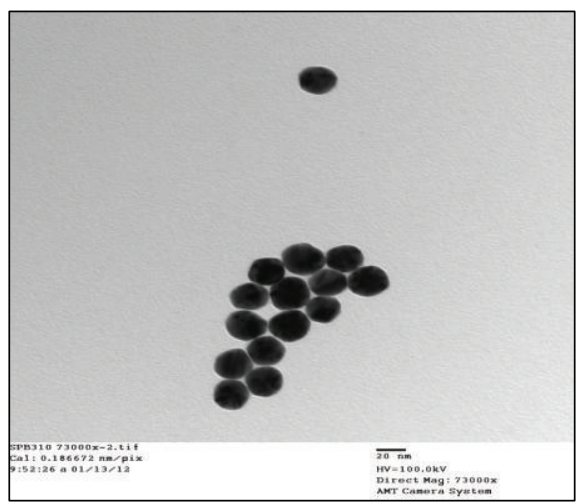

(c)

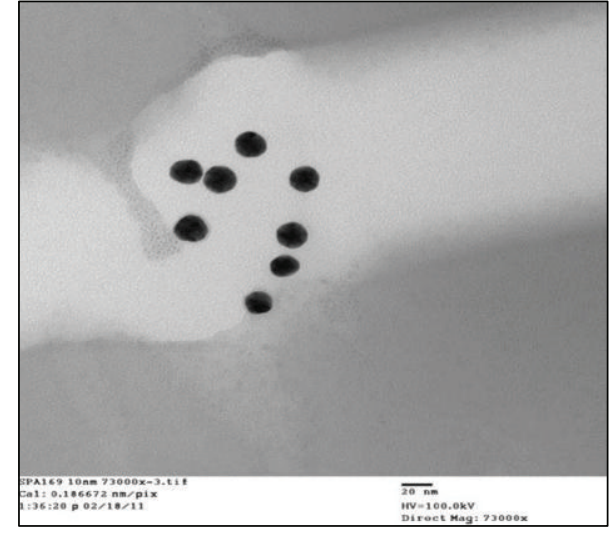

(b)

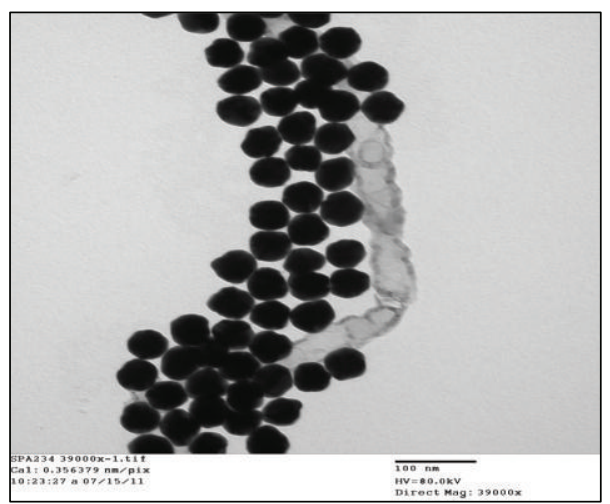

(d)

Figure 1: TEM images of (a) $3 \mathrm{~nm}$; (b) $10 \mathrm{~nm}$; (c) $25 \mathrm{~nm}$; and (d) $50 \mathrm{~nm}$ gold nanoparticles. The scale bars represent $20 \mathrm{~nm}$ (a)-(c) and $100 \mathrm{~nm}$ (d).

TABLE 2: MTT cytotoxicity assay of gold nanoparticles.

\begin{tabular}{lcccc}
\hline Nanoparticle concentration & \multicolumn{3}{c}{ Nanoparticles sizes } \\
& $3 \mathrm{~nm}$ & $10 \mathrm{~nm}$ & $25 \mathrm{~nm}$ & $100 \pm 0.13$ \\
$0 \mu \mathrm{g}$ & $100 \pm 0.27$ & $100 \pm 0.47$ & $97.21 \pm 0.11$ & $90.00 \pm 0.12$ \\
$0.5 \mu \mathrm{g}$ & $92.27 \pm 0.17$ & $96.87 \pm 0.25$ & $96.77 \pm 0.17$ & $96.17 \pm 0.09$ \\
$5.0 \mu \mathrm{g}$ & $90.21 \pm 0.30$ & $94.21 \pm 0.31$ & $95.16 \pm 0.04$ & $93.67 \pm 0.12$ \\
$10 \mu \mathrm{g}$ & $84.94 \pm 0.19$ & $93.07 \pm 0.16$ & $93.20 \pm 0.07$ & $90.72 \pm 0.08$ \\
$25 \mu \mathrm{g}$ & $83.01 \pm 0.30$ & $91.06 \pm 0.12$ & $84.28 \pm 0.12$ & $83.15 \pm 0.26$ \\
$50 \mu \mathrm{g}$ & $76.79 \pm 0.28$ & $84.78 \pm 0.09$ & \\
\hline
\end{tabular}

the GNPs and was reported to be 3, 10, 26, and 50 for the respective GNPs used in our studies. The zeta potentials for 3, 10, 25, and $50 \mathrm{~nm}$ GNPs were $-38.2,-49,-34$, and $40 \mathrm{mV}$, respectively (Table 1 ).

In addition to DLS analysis to evaluate the sizes of GNPs, TEM was performed to confirm the GNPs sizes. The TEM analysis of all of the GNPs 3, 10, 26, and $50 \mathrm{~nm}$ was consistent as expected for each GNP (Figures $1(\mathrm{a})-1(\mathrm{~d})$ ). As seen in the TEM images, all GNPs were spherical in shape.

3.2. Cell Cytotoxicity Assay. We used standard MTT assay to check the cytotoxicity of GNPs. Concentrations ranging from 0.5 to $50 \mu \mathrm{g} / \mathrm{mL}$ of each nanoparticle sample were tested for toxicity to HEp-2 cells by MTT assay (Table 2). The results showed that cell viability decreased to $80 \%$ at $50 \mu \mathrm{g} / \mathrm{mL}$ for $3 \mathrm{~nm}$ GNPs. The $3 \mathrm{~nm}$ GNPs exhibited the highest toxicity to the cells compared with other GNPs which were above $80 \%$ at similar concentrations.

3.3. SEM and AFM Analyses Show That $3 \mathrm{~nm}$ GNPs Accumulate in Cytoplasm and Nucleus and Damage Nuclear Membrane. Our SEM results showed that accumulation of GNPs in various cell organelles such as the cytoplasm and the nucleus is dependent on the size of GNPs and the duration of incubation within the cells. Similarly, GNPs sizes also have an impact on the damage to the cellular and nuclear 


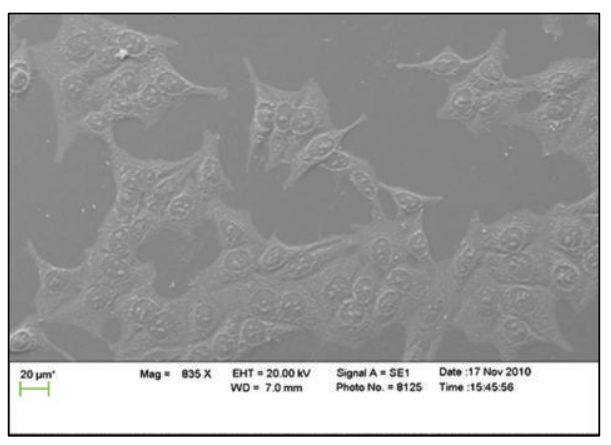

(a)

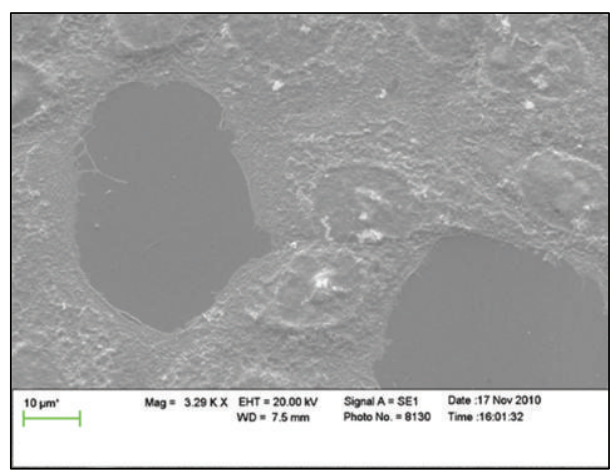

(c)

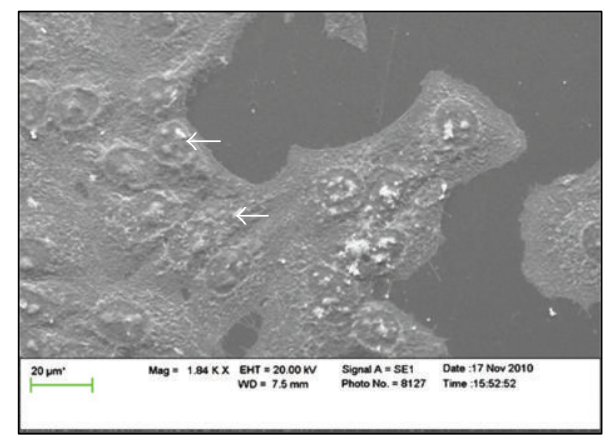

(b)

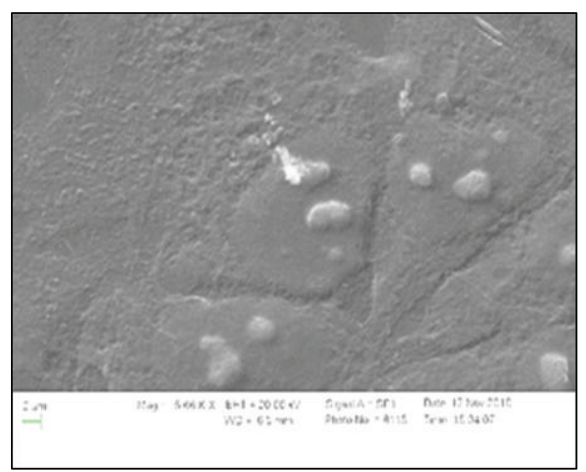

(d)

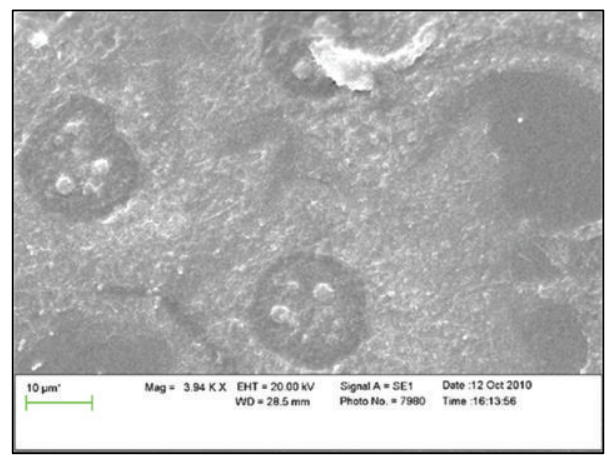

(e)

FIGURE 2: SEM imaging of $3 \mathrm{~nm}$ gold nanoparticles into HEp-2 cells after 1 (a), 2 (b), 4 (c), 12 (d), and 24 hr (e) incubations. Arrows indicating accumulation of GNPs.

membranes. The $3 \mathrm{~nm}$ GNPs were seen to accumulate in the cytoplasm after $1 \mathrm{hr}$ of incubation with the HEp- 2 cells (Figure 2(a)). The amount of accumulation increased as the incubation time progressed. Higher amounts of GNPs are observed in the cytoplasm after $2 \mathrm{hr}$ incubation (Figure 2(b)). In addition, GNPs entered the nucleus within $2 \mathrm{hr}$ incubation time (as shown by the arrows in Figure 2(b)). As the GNPs incubation period with cells increased to $4 \mathrm{hr}$ (Figure 2(c)) and $12 \mathrm{hr}$ (Figure 2(d)), damage to the nuclear membrane was obvious. After $12 \mathrm{hr}$ incubation, the majority of the nuclear membrane was damaged. After $24 \mathrm{hr}$ incubation, none of the cellular membranes was intact (Figure 2(e)). This was an indication that $3 \mathrm{~nm}$ GNPs are very efficient in entering the cytoplasm and nucleus within 1-2 hr of incubation, and eventually these GNPs are capable of damaging cellular membranes and killing the cells in 8-12 hr.

Our AFM data also corroborate the SEM microscopy results in that, after $1 \mathrm{hr}$ of incubation, the $3 \mathrm{~nm}$ gold nanoparticles entered the nucleus (arrow in Figure 3(a)). They continued to accumulate in both the cytoplasm and the nucleus as the incubation time progressed (highlighted by the ellipsoids in Figures 3(b)-3(e)). After $24 \mathrm{hr}$ incubation, most of the nuclear as well as cellular membranes were damaged (Figure 3(e)). Cytoplasm and Nucleus. The goal of this study was to assess 


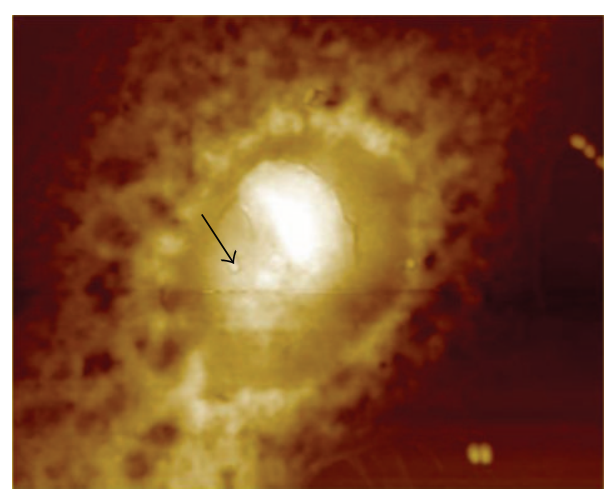

(a)

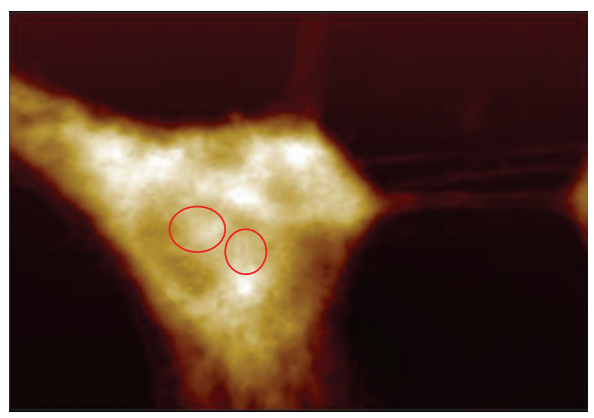

(c)

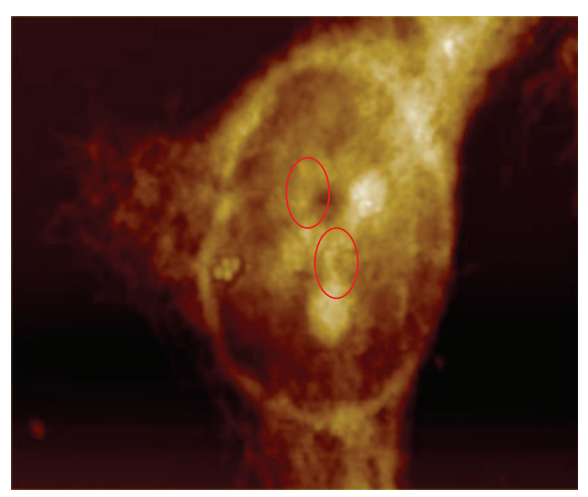

(b)

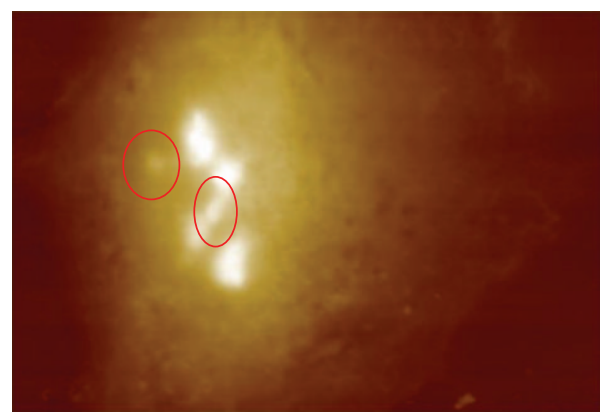

(d)

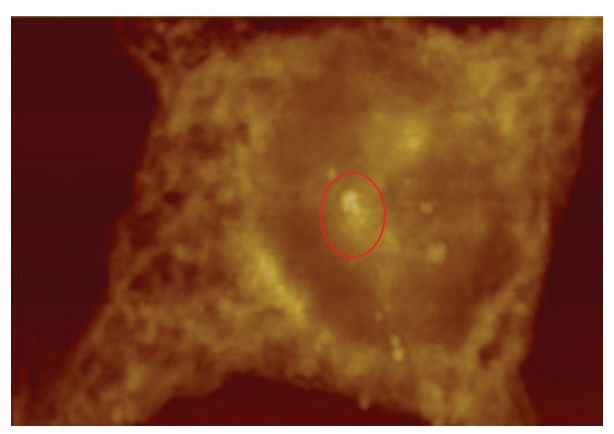

(e)

FIGURE 3: AFM imaging of $3 \mathrm{~nm}$ gold nanoparticles into HEp-2 cells after 1 (a), 2 (b), 4 (c), 12 (d), and 24 hr (e) incubations. All images are 45 by 45 microns.

the uptake of GNPs by HEp-2 cell lines, taking into account factors such as gold nanoparticles sizes and incubation time. We continued our experiments for $1,2,4,12$, and $24 \mathrm{hr}$ to analyze the accumulation of GNPs at various time intervals. As seen in SEM images, after $1 \mathrm{hr}$ incubation, $10 \mathrm{~nm}$ GNPs start to accumulate on the surface of the cellular membrane (Figure 4(a)) and begin to enter the cytoplasm and the nucleus after $2 \mathrm{hr}$ (Figure 4(b)). It is clear from SEM imaging that $10 \mathrm{~nm}$ GNPs begin to enter the nucleus and the amount of GNPs accumulation increases as the incubation time increases (Figures 4(c)-4(d)). The highest amounts of GNPs were observed at $12 \mathrm{hr}$ exposure. The amount of GNPs accumulation in the nucleus and surrounding nucleus also corresponds to the increased nuclear membrane damage. After $12 \mathrm{hr}$ of exposure, majority of the nuclear membrane has been damaged, and there is no apparent nucleus present within the cell.

Similar to the $3 \mathrm{~nm}$ GNPs, we observed that $10 \mathrm{~nm}$ GNPs show high amount of accumulation in the nucleus within $4 \mathrm{hr}$ of incubation. As compared with the $3 \mathrm{~nm}$ GNPs, $10 \mathrm{~nm}$ GNPs accumulate at a slower rate, and the damage of the nuclear membrane takes place after $12 \mathrm{hr}$, while $3 \mathrm{~nm}$ GNPs damage the nuclear membrane before $12 \mathrm{~h}$.

Similar to the SEM images, AFM studies reveal the same pattern where $10 \mathrm{~nm}$ GNPs start to accumulate (arrow in Figure 5(a)) and enter the nucleus (ellipsoids in Figure 5(b)) within $2 \mathrm{hr}$ of incubation, and higher amounts of GNPs are observed to cluster within the nucleus over $12 \mathrm{hr}$ of exposure (ellipsoids highlights in Figures 5(c) and 5(d)). The nuclear membrane damage is evident after $12 \mathrm{hr}$ incubation, and 


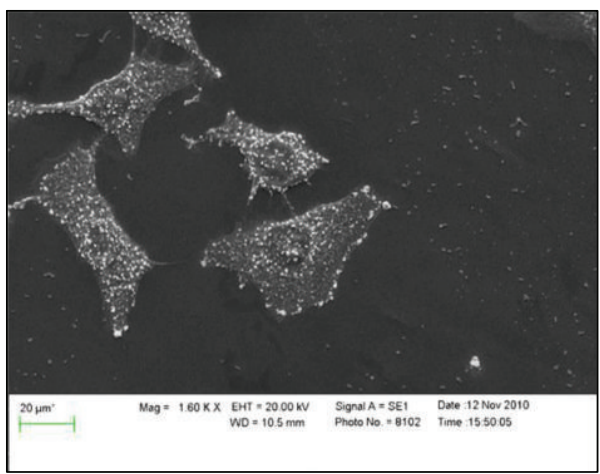

(a)

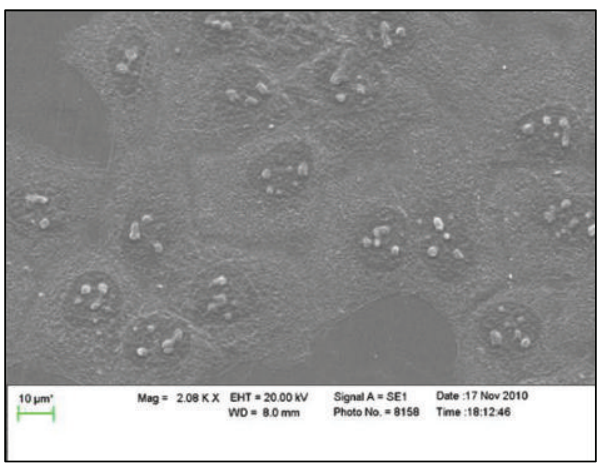

(c)

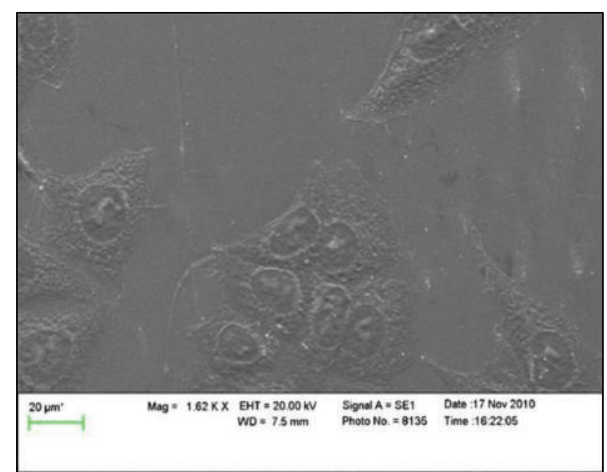

(b)

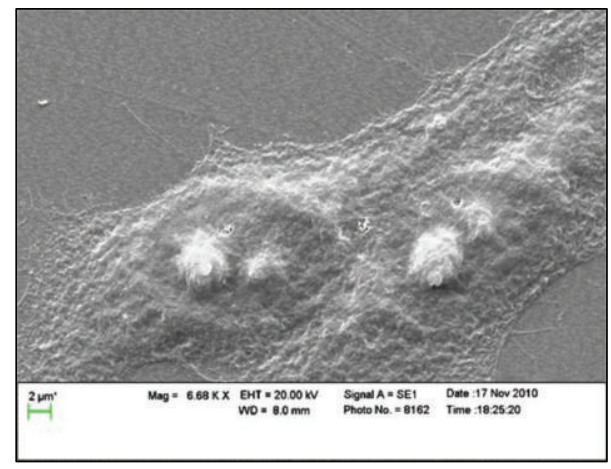

(d)

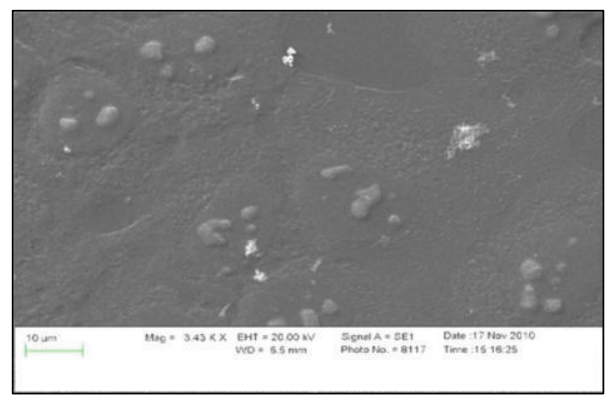

(e)

FIGURE 4: SEM imaging of $10 \mathrm{~nm}$ gold nanoparticles into HEp-2 cells after 1 (a), 2 (b), 4 (c), 12 (d), and 24 hr (e) incubations.

the greatest damage to the nuclear membrane is seen after $24 \mathrm{hr}$ (Figure 5(e)). From these images, it is evident that the accumulation of $10 \mathrm{~nm}$ GNPs increases as the exposure time increases reaching a maximum accumulation at $24 \mathrm{hr}$.

\subsection{GNPs of $25 \mathrm{~nm}$ Size Enter the Cytoplasm and Surround} the Nuclear Membrane. The size-dependent entry into cells was also analyzed using $25 \mathrm{~nm}$ GNPs and their exposure to cells at various time intervals. The SEM studies showed that $25 \mathrm{~nm}$ GNPs enter the cytoplasm after $2 \mathrm{hr}$ of exposure (Figures 6(a) and 6(b)). A small number of $25 \mathrm{~nm}$ GNPs are present in the nucleus after $12 \mathrm{hr}$ (Figure 6(d)) which increases after $24 \mathrm{hr}$ exposure (Figure 6(e)). As expected, the larger nanoparticles can enter the cytoplasm, but entry into the nucleus is restricted due to the smaller nuclear pores, which typically control the entry of molecules into the nucleus.

AFM images follow the same pattern as SEM and show that $25 \mathrm{~nm}$ GNPs are seen after $1 \mathrm{hr}$ incubation (indicated by the arrow in Figure 7(a)), but their presence in the cytoplasm is evident after $2 \mathrm{hr}$ exposure (Figure $7(\mathrm{~b})$ ). The GNPs are seen in the nucleus after $12 \mathrm{hr}$ (circle in Figure $7(\mathrm{~d})$ ) and $24 \mathrm{hr}$ (circle in Figure 7(e)) incubations. The cells exposed to $25 \mathrm{~nm}$ GNPs after $24 \mathrm{hr}$ incubation show higher amount of accumulation in nucleus due to apparent nuclear membrane damage.

3.6. SEM and AFM Analyses Show That $50 \mathrm{~nm}$ GNPs Do Not Enter the Nucleus. In contrast to the previous nanoparticles, the $50 \mathrm{~nm}$ GNPs accumulate at the cell membrane at $1 \mathrm{hr}$ 


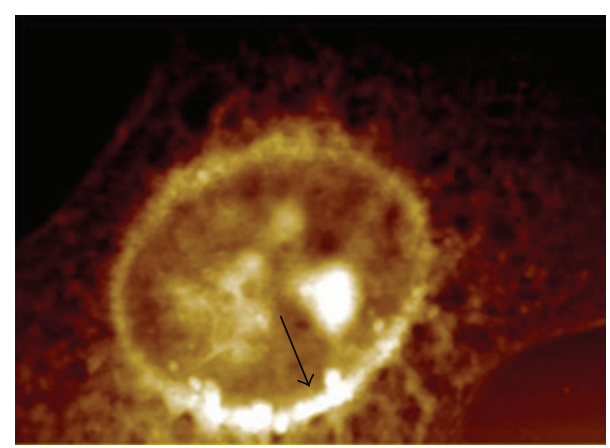

(a)

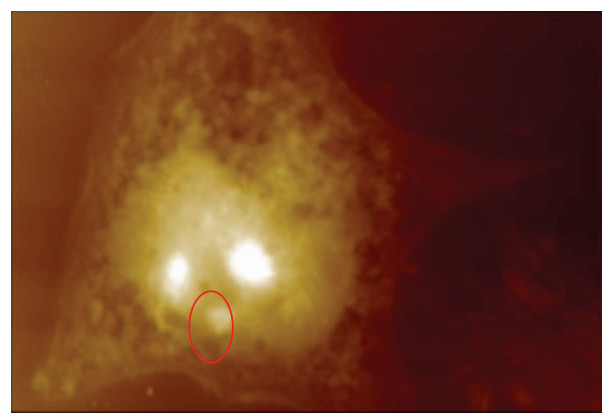

(c)

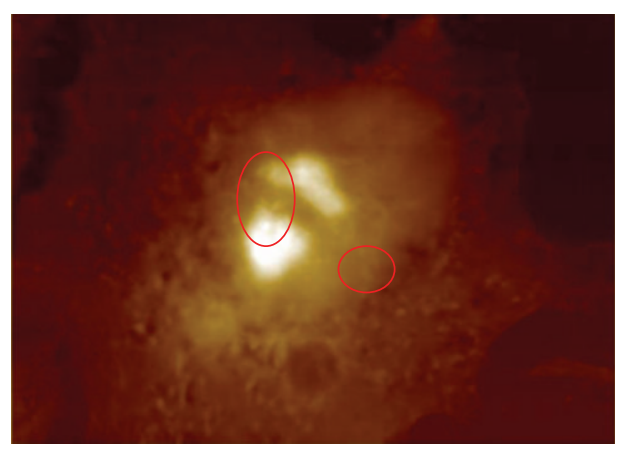

(b)

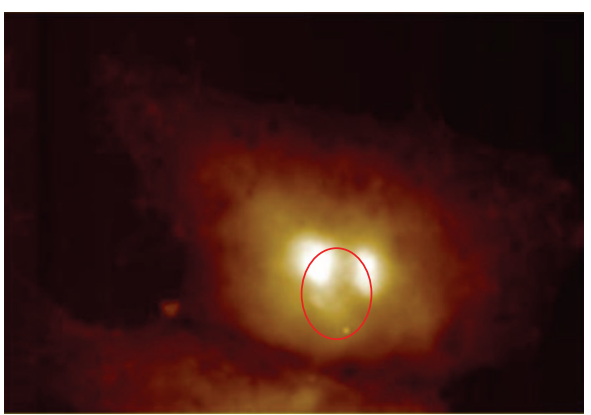

(d)

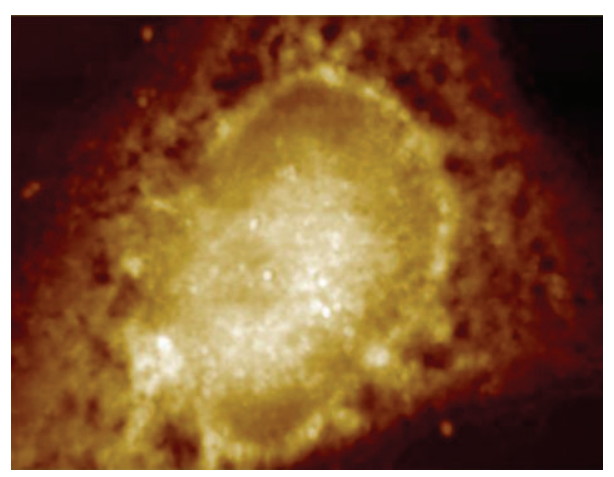

(e)

FIGURE 5: AFM imaging of $10 \mathrm{~nm}$ gold nanoparticles into HEp-2 cells after 1 (a), 2 (b), 4 (c), 12 (d), and 24 hr (e) incubations. All images are 45 by 45 microns.

exposure (Figure 8(a)). However, after $2 \mathrm{hr}$ incubation, very small amounts of GNPs are seen in the cytoplasm. The GNPs concentration in the cytoplasm increases slowly after $4 \mathrm{hr}$ and reaches a maximum after $12 \mathrm{hr}$ exposure (Figure $8(\mathrm{~d})$ ). A very small number of $50 \mathrm{~nm}$ GNPs are seen in the nucleus after $24 \mathrm{hr}$ exposure (Figure 8(e)). Damage to the nuclear membrane is also observed, but not to the same degree as seen in the smaller GNPs sizes.

Following the same trend as SEM, AFM images show that a large number of GNPs are present at the cell membrane after $1 \mathrm{hr}$ incubation (arrows in Figure 9(a)), but they are not as visible after $2 \mathrm{hr}$ incubation (Figure 9(b)). The AFM images of cells incubated for $12 \mathrm{hr}$ (Figure 9(d)) and $24 \mathrm{hr}$ (Figure 9(e)) show that the nuclear membrane is not affected by the $50 \mathrm{~nm}$ GNPs exposure. Although $50 \mathrm{~nm}$ GNPs were not able to enter the nucleus effectively like $3 \mathrm{~nm}$ and $10 \mathrm{~nm}$ GNPs, they were able to damage the cellular membrane as the exposure time progressed. The damage to the cell membrane by $50 \mathrm{~nm}$ GNPs is seen in the AFM images (Figures 9(c)-9(e)).

One of the major obstacles in using nanoparticles as therapeutics is their potential toxicity to cells. Our MTT analysis showed that $3 \mathrm{~nm}$ GNPs exhibited the highest toxicity as compared with the other sizes of GNPs (10, 25, and $50 \mathrm{~nm}$ ). It has been documented that particle size plays a significant role on the toxicity of GNPs [5, 15, 21]. Tsoli et al. reported that the smallest GNPs (nanoparticle size of approximately $1 \mathrm{~nm}$ ) exhibit the highest toxicity due to the fact that they can penetrate both the cellular and the nuclear membranes and become attached to DNA molecules more easily than larger nanoparticles. In contrast, Uboldi et al. [22] demonstrated that nanoparticle size had no significant impact on the toxicity of GNPs, but the sodium citrate 


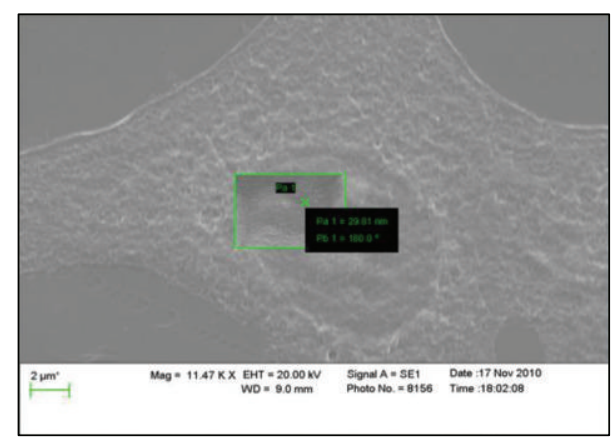

(a)

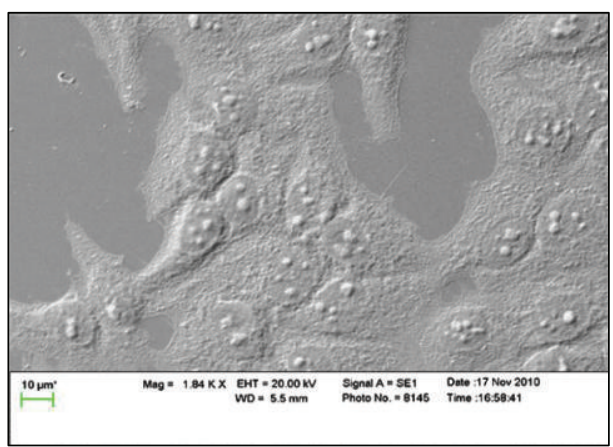

(c)

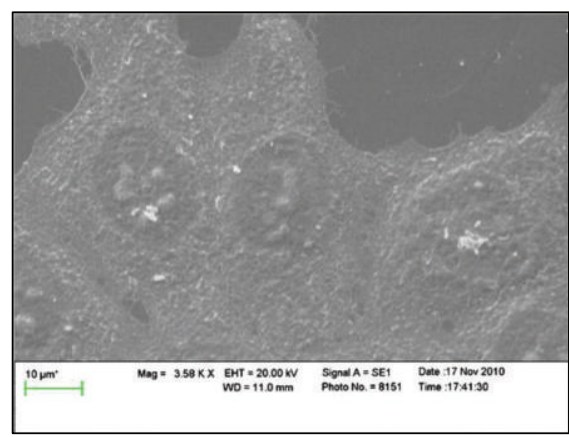

(b)

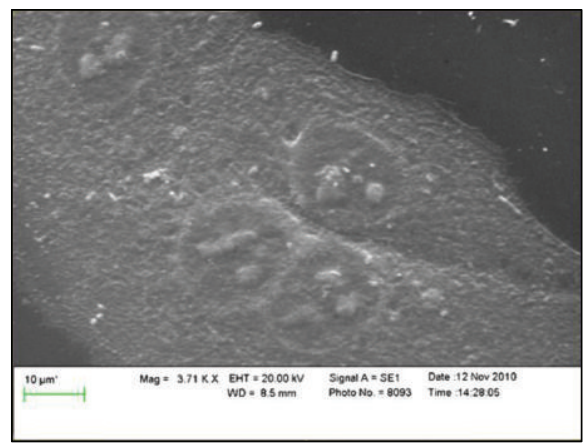

(d)

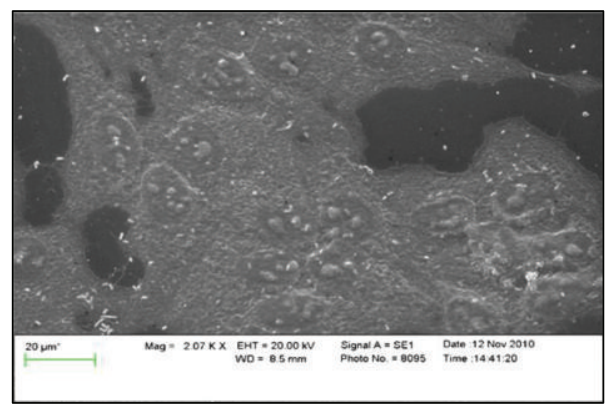

(e)

FiguRE 6: SEM imaging of $25 \mathrm{~nm}$ gold nanoparticles into HEp-2 cells after 1 (a), 2 (b), 4 (c), 12 (d), and 24 hr (e) incubations.

used in the synthesis of GNPs interfered with the cells and contributed to cell cytotoxicity. GNPs have been reported as either toxic or nontoxic [15] depending on the experimental design, nanoparticle synthesis method, and type of GNPs under study.

Our data show that most GNPs used in our studies entered the cytoplasm at different rates depending on the nanoparticle size and incubation time. SEM and AFM results showed that 3 and $10 \mathrm{~nm}$ GNPs enter the nucleus efficiently whereas a majority of 25 , and $50 \mathrm{~nm}$ GNPs remain in the cytoplasm. According to our results, GNPs of $3 \mathrm{~nm}$ and $10 \mathrm{~nm}$ enter the nucleus without any regulation, whereas entry of $25 \mathrm{~nm}$ and $50 \mathrm{~nm}$ nanoparticles is limited based on size exclusivity and requires the transport receptors. In agreement with our studies, the Berry group reported that GNPs of $5 \mathrm{~nm}$ functionalized with HIV protein enter the nucleus [23]. Our studies are not in agreement with the studies of $\mathrm{Oh}$ et al. who reported that GNPs of $2.4 \mathrm{~nm}$ enter the nucleus, that 5.5 and $8.2 \mathrm{~nm}$ GNPs are perinuclear, and that those above $16 \mathrm{~nm}$ do not enter cells [24]. The difference in studies may be due to the cells and conditions of treatment, particularly functionalization of the GNPs. In addition, we have used a variety of incubation times and a different cell type that may explain the difference in results. It is clear that GNPs of smaller sizes have better entry into the cells and they can find their way into the nucleus.

Since we observed that $3 \mathrm{~nm}$ GNPs enter into the nucleus, these spherical GNPs may find applications in gene and drug delivery even without any conjugation. It has been demonstrated that small nanoparticles $(1-5 \mathrm{~nm})$ are more suitable to interact with DNA molecules than larger nanoparticles [22]. The combination of GNPs with DNA molecules has been reported in gene delivery [25-27], nanosensors [4], and the detection of single-nucleotide polymorphisms (SNPs) 


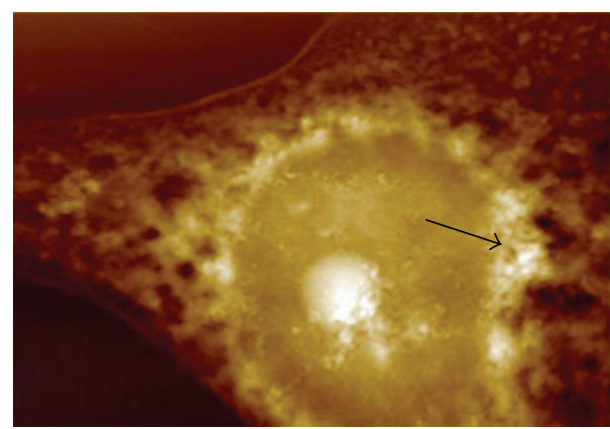

(a)

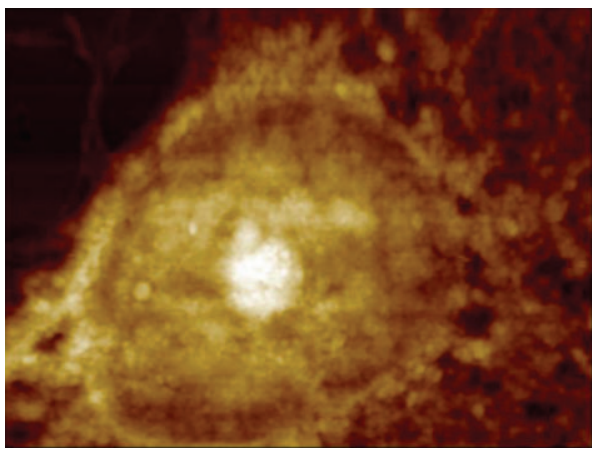

(c)

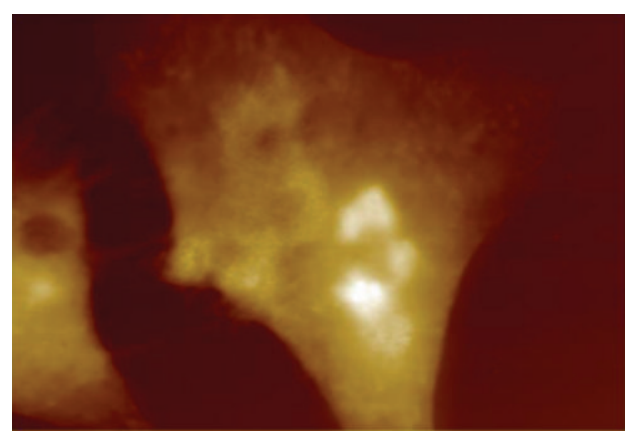

(b)

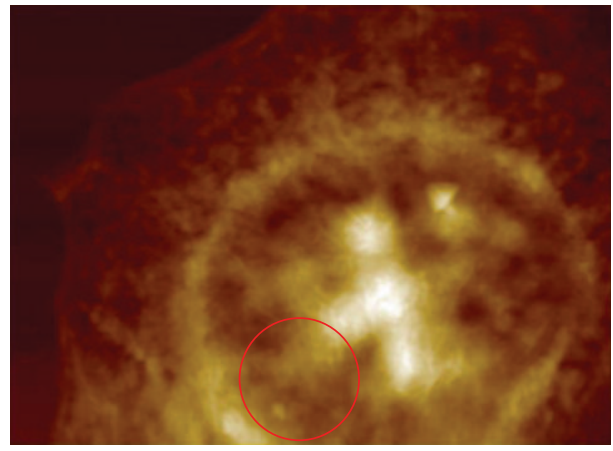

(d)

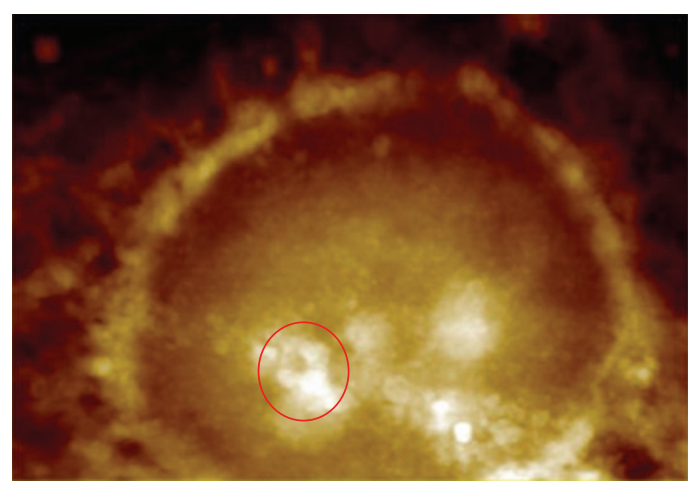

(e)

FigURE 7: AFM imaging of $25 \mathrm{~nm}$ gold nanoparticles into HEp-2 cells after 1 (a), 2 (b), 4 (c), 12 (d), and 24 hr (e) incubations. All images are 45 by 45 microns, except for images (b) and (e) which are 40 by 40 microns.

[28]. In these applications, cationic GNPs and negatively charged DNA molecules interacted and formed a suitable DNA delivery carrier.

We show that $10 \mathrm{~nm}$ GNPs can also efficiently enter the cytoplasm and the nucleus. Klein et al. have shown that $15 \mathrm{~nm}$ GNPs are very efficient in entering the cells [29]. Additional studies [30] show that bare and PEG-coated $15 \mathrm{~nm}$ GNPs were able to enter the cells. The plain GNPs entered the cytosol efficiently, while the PEG-functionalized GNPs entered the cytosol in much lower numbers. The PEG-functionalized GNPs are most likely larger, which may limit their entry into cells. They indicated the role of endocytotic as well as nonendocytotic mechanisms involved in trafficking GNPs in cells. In addition, the duration of exposure time plays a role in the accumulation in the cytosol, which is in agreement with our studies.

Our SEM and AFM images show that nonconjugated $25 \mathrm{~nm}$ GNPs have limited access to the nucleus due to the restriction posed by the nuclear membrane. Studies of Kang et al. show that $30 \mathrm{~nm}$ GNPs conjugated with arginineglycine-aspartic acid (RGD) peptide and nuclear localization signal (NLS) peptide for anticancer therapy enter the nucleus of cancer cells [31]. They concluded that conjugated GNPs reduced the viability of cancer cells, because of their accumulation in the nucleus, resulting in disruption of cell morphology and functionality. It was suggested that there is an extensive difference between the cellular uptakes of conjugated and nonconjugated nanoparticles. The nuclear 


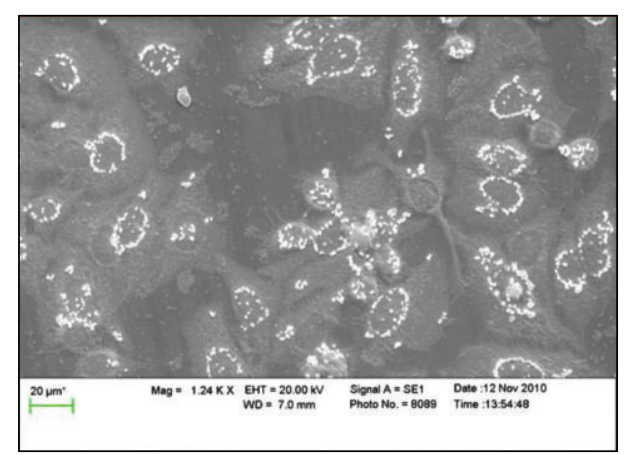

(a)

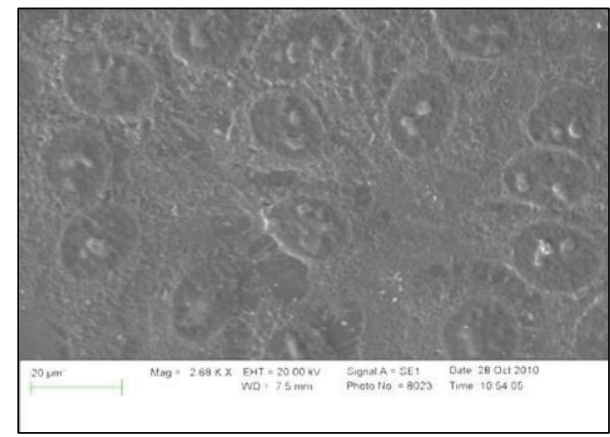

(c)

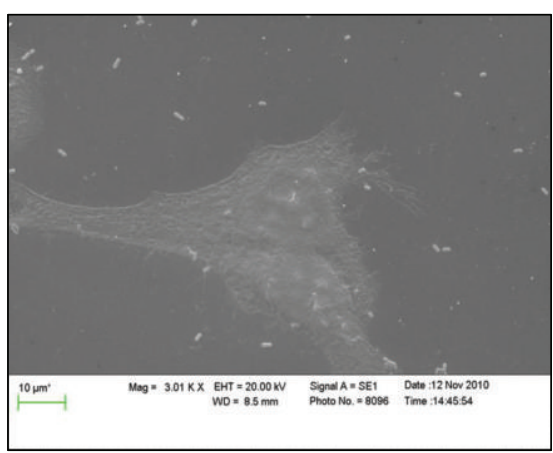

(b)

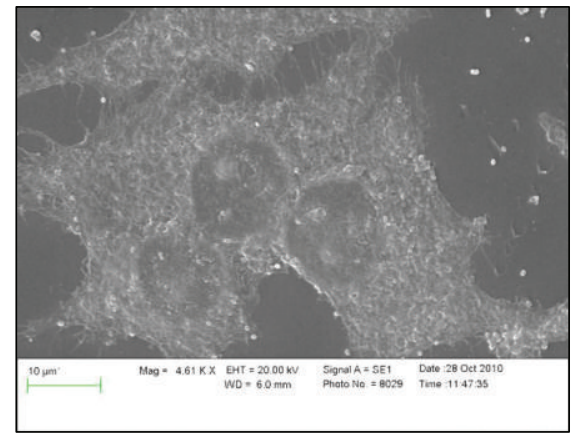

(d)

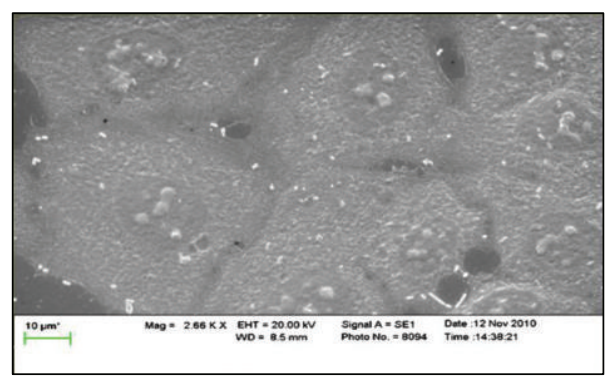

(e)

FIGURE 8: SEM imaging of $50 \mathrm{~nm}$ gold nanoparticles into HEp-2 cells after 1 (a), 2 (b), 4 (c), 12 (d), and 24 hr (e) incubations.

peptides used by Kang et al. must have facilitated a higher amount of GNPs entry into the nucleus and death of cancer cells as opposed to our $25 \mathrm{~nm}$ GNPs which show limited nuclear accumulation.

Our finding that $50 \mathrm{~nm}$ plain spherical GNPs enter cells efficiently is in agreement with a previous report showing that GNPs of $50 \mathrm{~nm}$ enter the cells efficiently [32]. However, $50 \mathrm{~nm}$ GNPs functionalized with PEG or proteins lead to a reduced cellular uptake. The functionalized GNPs most likely have an increased size that hinders their entry into cells. In another study by Wang et al. [33], it was shown that $45 \mathrm{~nm}$ GNPs enter the cells but not the nucleus, which supports our finding. In addition, entry into the cells was attributed to the endocytosis mechanism. All higher GNPs failed to enter the cytoplasm and accumulated on cell surface. We also observed accumulation of $50 \mathrm{~nm}$ GNPs on the cell surface, especially at shorter exposure times. The presence of $60 \mathrm{~nm}$ GNPs in cytoplasm has also been confirmed by Klein et al. [29].

It has been documented that the cellular uptake of nanoparticles is based on the interactions between membrane receptors and the surfaces of nanoparticles. The $50 \mathrm{~nm}$ GNPs exhibit receptor-mediated endocytosis for intracellular uptake $[9,10,34]$. Osaki et al. report that $50 \mathrm{~nm}$ GNPs exhibit the most suitable intracellular uptake, because these particles are facilitated by receptor-mediated endocytosis. Similarly, Gao et al. found that $55 \mathrm{~nm}$ GNPs might be taken up by cells at the shortest wrapping time, because $55 \mathrm{~nm}$ is the most efficient size to produce free energy, which is required for the transportation of GNPs into the cells. Nanoparticles smaller than $50 \mathrm{~nm}$ nanoparticle size cannot adequately produce free energy for complete wrapping, whereas larger nanoparticles are not able to produce a passable combination with surface 


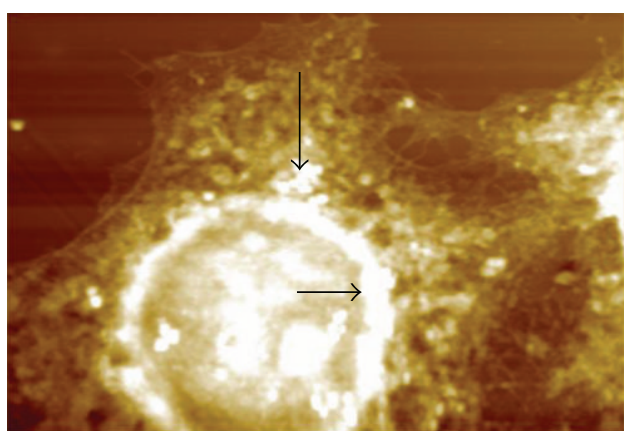

(a)

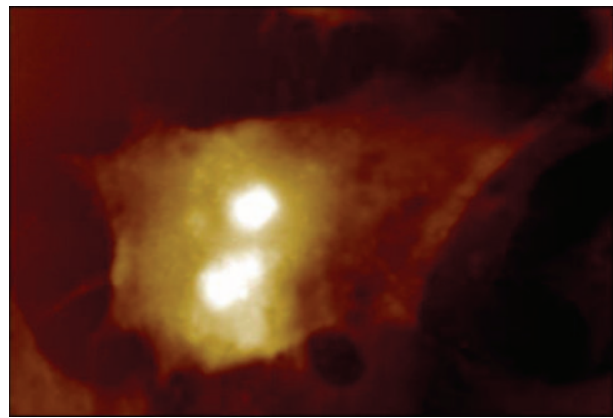

(c)

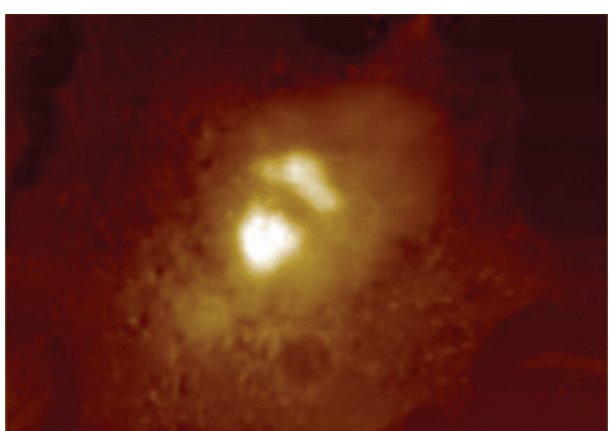

(b)

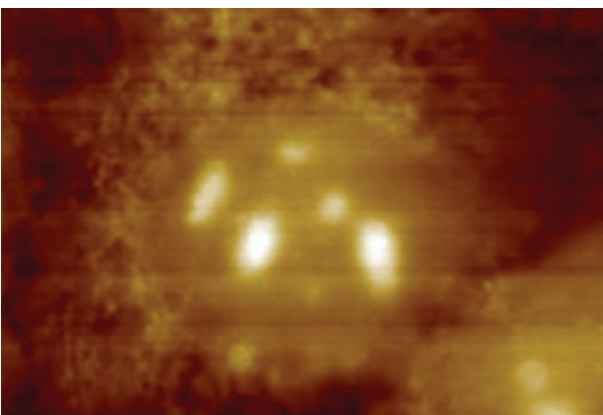

(d)

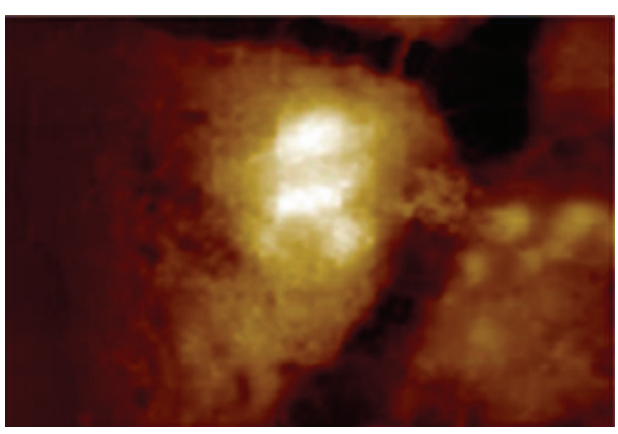

(e)

Figure 9: AFM imaging of $50 \mathrm{~nm}$ gold nanoparticles into HEp-2 cells after 1 (a), 2 (b), 4 (c), 12 (d), and 24 hr (e) incubations. All images are 45 by 45 microns except for (e) which is 40 by 40 microns.

receptors in order to enter into the cells. In agreement with the previous studies, we show that $50 \mathrm{~nm}$ GNPs enter the cytoplasm, but their concentrations within the cells are highly dependent on the exposure time. Our studies also demonstrate that nuclear localization of $50 \mathrm{~nm}$ GNPs is restricted most likely due to the nuclear pore complexes consisting of 30 different protein components described as nucleoporins or nups, which are responsible for nuclear transportation [35].

GNPs have received a great deal of attention for their multipurpose biomedical applications. GNPs have been shown to be potent against different viruses, such as HIV [36] and influenza [37]. In these studies, functionalized GNPs were used to inhibit viral infections via multivalent interactions between the surfaces of the nanoparticles and the viral proteins. In these studies, size variations significantly affected the viral inhibition properties of GNPs. For example, Papp et al. used $2 \mathrm{~nm}$ and $14 \mathrm{~nm}$ GNPs in order to measure the potential inhibition of the influenza virus. They reported that $14 \mathrm{~nm}$ GNPs are more effective than $2 \mathrm{~nm}$ ones because the interaction between particles surfaces and viral proteins was more efficiently supported by larger surfaces. Based on our studies, it is obvious that these GNPs are present in the cytoplasm and the nucleus, and thus the inhibition of virus will depend solely on the interaction between the viral protein and the GNPs. GNPs below $20 \mathrm{~nm}$ may be useful for DNA viruses, while larger sizes of GNPs could work better for RNA viruses. This is due to the fact that RNA viruses rely on cellular machinery in the cytoplasm for viral protein expression and viral assembly, while DNA viruses heavily rely on nuclear transcription process for viral protein manufacturing.

It is obvious from various studies that the entry of GNPs into the cells and the nucleus depends on size, shape, concentration of GNPs, factors leading to agglomeration, time of incubation, types of cells used, media and proteins 
present in the media, ratio of adhesion, and several other factors $[9,10,34,38]$. In addition, other cellular mechanisms for entry of nanoparticles into cells such as phagocytosis, clathrin-mediated endocytosis, caveolae-mediated endocytosis, and nonclathrin- and noncaveolae-mediated endocytoses are involved [39]. Therefore, these factors must be considered for use and application of a specific GNP for biomedical applications, particularly where cytoplasmic or nuclear localization of GNPs is required.

\section{Conclusions}

In this work, we attempted to identify the biophysical uptakes of different sizes of plain GNPs in vitro. We demonstrated the importance of size variations of GNPs that will guide their applications in the field of nanomedicine and nanobiotechnology. We showed that $3 \mathrm{~nm}$ and $10 \mathrm{~nm}$ GNPs enter the cytoplasm and the nucleus effectively and damage the cellular as well as the nuclear membranes. The membrane damage leads to high toxicity of smaller GNPs such as those of $3 \mathrm{~nm}$ and $10 \mathrm{~nm}$ sizes. The $25 \mathrm{~nm}$ GNPs are not as effective in entering the nucleus and cause less damage to the cell. The $50 \mathrm{~nm}$ GNPs do not enter the nucleus rendering minimal cell damage. The damage to the cells caused by $50 \mathrm{~nm}$ GNPs is due to the accumulation of GNPs on the cell surface. The application of smaller GNPs (3 and $10 \mathrm{~nm}$ ) may be useful for DNA viral inhibition, while larger GNPs (25 and $50 \mathrm{~nm}$ ) could be better for RNA viral inhibition. For anticancer applications, GNPs with less than $20 \mathrm{~nm}$ sizes may be useful. Our studies, along with previous others, indicated that cytoplasmic and nuclear uptakes of GNPs depend on size and biophysical properties of GNPs as well as the cellular mechanisms for entry of nanoparticles.

\section{Acknowledgments}

The authors would like to thank Dr. Michael Miller for his assistance with SEM analysis of samples. This work was supported by the National Science Foundation CREST Program (HRD-1241701) Grant.

\section{References}

[1] P. K. Jain, X. Huang, I. H. El-Sayed, and M. A. El-Sayed, "Noble metals on the nanoscale: optical and photothermal properties and some applications in imaging, sensing, biology, and medicine," Accounts of Chemical Research, vol. 41, no. 12, pp. 1578-1586, 2008.

[2] S. Dhar, E. Maheswara Reddy, A. Shiras, V. Pokharkar, and B. L. V. Prasad, "Natural gum reduced/stabilized gold nanoparticles for drug delivery formulations," Chemistry, vol. 14, no. 33, pp. 10244-10250, 2008.

[3] H. M. Joshi, D. R. Bhumkar, K. Joshi, V. Pokharkar, and M. Sastry, "Gold nanoparticles as carriers for efficient transmucosal insulin delivery," Langmuir, vol. 22, no. 1, pp. 300-305, 2006.

[4] L. Olofsson, T. Rindzevicius, I. Pfeiffer, M. Käll, and F. Höök, "Surface-based gold-nanoparticle sensor for specific and quantitative DNA hybridization detection," Langmuir, vol. 19, no. 24, pp. 10414-10419, 2003.
[5] Y. Pan, S. Neuss, A. Leifert et al., "Size-dependent cytotoxicity of gold nanoparticles," Small, vol. 3, no. 11, pp. 1941-1949, 2007.

[6] L. Zang, Y. Che, and J. S. Moore, "One-dimensional selfassembly of planar pi-conjugated molecules: adaptable building blocks for organic nanodevices," Accounts of Chemical Research, vol. 41, no. 12, pp. 1596-1608, 2008.

[7] H. Ringsdorf, B. Schlarb, and J. Venzmer, "Molecular architecture and function of polymeric oriented systems: models for the study of organization, surface recognition, and dynamics of biomembrnaes," Angewandte Chemie, vol. 27, no. 1, pp. 113-158, 1988.

[8] W. S. Cho, M. Cho, J. Jeong et al., "Acute toxicity and pharmacokinetics of $13 \mathrm{~nm}$-sized PEG-coated gold nanoparticles," Toxicology and Applied Pharmacology, vol. 236, no. 1, pp. 16-24, 2009.

[9] B. D. Chithrani, A. A. Ghazani, and W. C. W. Chan, "Determining the size and shape dependence of gold nanoparticle uptake into mammalian cells," Nano Letters, vol. 6, no. 4, pp. 662-668, 2006.

[10] F. Osaki, T. Kanamori, S. Sando, T. Sera, and Y. Aoyama, "A quantum dot conjugated sugar ball and its cellular uptake. On the size effects of endocytosis in the subviral region," Journal of the American Chemical Society, vol. 126, no. 21, pp. 6520-6521, 2004.

[11] J. D. Gibson, B. P. Khanal, and E. R. Zubarev, "Paclitaxelfunctionalized gold nanoparticles," Journal of the American Chemical Society, vol. 129, no. 37, pp. 11653-11661, 2007.

[12] S. J. Yoon, S. Mallidi, J. M. Tam et al., "Utility of biodegradable plasmonic nanoclusters in photoacoustic imaging," Optics Letters, vol. 35, no. 22, pp. 3751-3753, 2010.

[13] W. Huang, W. Qian, P. K. Jain, and M. A. El-Sayed, “The effect of plasmon field on the coherent lattice phonon oscillation in electron-beam fabricated gold nanoparticle pairs," Nano Letters, vol. 7, no. 10, pp. 3227-3234, 2007.

[14] G. Saikia, A. Murugadoss, P. J. Sarmah, A. Chattopadhyay, and P. K. Iyer, "Tuning the optical characteristics of poly(pphenylenevinylene) by in situ Au nanoparticle generation," Journal of Physical Chemistry B, vol. 114, no. 46, pp. 14821-14826, 2010.

[15] E. E. Connor, J. Mwamuka, A. Gole, C. J. Murphy, and M. D. Wyatt, "Gold nanoparticles are taken up by human cells but do not cause acute cytotoxicity," Small, vol. 1, no. 3, pp. 325-327, 2005.

[16] D. P. O’Neal, L. R. Hirsch, N. J. Halas, J. D. Payne, and J. L. West, "Photo-thermal tumor ablation in mice using near infraredabsorbing nanoparticles," Cancer Letters, vol. 209, no. 2, pp. 171$176,2004$.

[17] W. H. de Jong, W. I. Hagens, P. Krystek, M. C. Burger, A. J. A. M. Sips, and R. E. Geertsma, "Particle size-dependent organ distribution of gold nanoparticles after intravenous administration," Biomaterials, vol. 29, no. 12, pp. 1912-1919, 2008.

[18] A. Kumar, H. Ma, X. Zhang et al., "Gold nanoparticles functionalized with therapeutic and targeted peptides for cancer treatment," Biomaterials, vol. 33, no. 4, pp. 1180-1189, 2012.

[19] R. Wilson, "The use of gold nanoparticles in diagnostics and detection," Chemical Society Reviews, vol. 37, no. 9, pp. 20282045, 2008.

[20] S. Song, L. Wang, J. Li, C. Fan, and J. Zhao, "Aptamer-based biosensors," TrAC Trends in Analytical Chemistry, vol. 27, no. 2, pp. 108-117, 2008. 
[21] M. Tsoli, H. Kuhn, W. Brandau, H. Esche, and G. Schmid, "Cellular uptake and toxicity of $\mathrm{Au}_{55}$ clusters," Small, vol. 1, no. 8-9, pp. 841-844, 2005.

[22] C. Uboldi, D. Bonacchi, G. Lorenzi et al., "Gold nanoparticles induce cytotoxicity in the alveolar type-II cell lines A549 and NCIH441," Particle and Fibre Toxicology, vol. 6, article 18, 2009.

[23] C. C. Berry, J. M. de la Fuente, M. Mullin, S. W. L. Chu, and A. S. G. Curtis, "Nuclear localization of HIV-1 tat functionalized gold nanoparticles," IEEE Transactions on Nanobioscience, vol. 6, no. 4, pp. 262-269, 2007.

[24] E. Oh, J. B. Delehanty, K. E. Sapsford et al., "Cellular uptake and fate of PEGylated gold nanoparticles is dependent on both cellpenetration peptides and particle size," ACS Nano, vol. 5, no. 8, pp. 6434-6448, 2011.

[25] P. S. Ghosh, C.-K. Kim, G. Han, N. S. Forbes, and V. M. Rotello, "Efficient gene delivery vectors by tuning the surface charge density of amino acid-functionalized gold nanoparticles," ACS Nano, vol. 2, no. 11, pp. 2213-2218, 2008.

[26] N. L. Rosi, D. A. Giljohann, C. S. Thaxton, A. K. R. Lytton-Jean, M. S. Han, and C. A. Mirkin, "Oligonucleotide-modified gold nanoparticles for infracellular gene regulation," Science, vol. 312, no. 5776, pp. 1027-1030, 2006.

[27] M. P. Rout, J. D. Aitchison, A. Suprapto, K. Hjertaas, Y. Zhao, and B. T. Chait, "The yeast nuclear pore complex: composition, architecture, transport mechanism," Journal of Cell Biology, vol. 148, no. 4, pp. 635-651, 2000.

[28] J. Chen, F. Saeki, B. J. Wiley et al., "Gold nanocages: bioconjugation and their potential use as optical imaging contrast agents," Nano Letters, vol. 5, no. 3, pp. 473-477, 2005.

[29] S. Klein, S. Petersen, U. Taylor, D. Rath, and S. Barcikowski, "Quantitative visualization of colloidal and intracellular gold nanoparticles by confocal microscopy," Journal of Biomedical Optics, vol. 15, no. 3, article 036015, 2010.

[30] C. Brandenberger, C. Mühlfeld, Z. Ali et al., "Quantitative evaluation of cellular uptake and trafficking of plain and polyethylene glycol-coated gold nanoparticles," Small, vol. 6, no. 15, pp. 1669-1678, 2010.

[31] B. Kang, M. A. Mackey, and M. A. El-Sayed, "Nuclear targeting of gold nanoparticles in cancer cells induces DNA damage, causing cytokinesis arrest and apoptosis," Journal of the American Chemical Society, vol. 132, no. 5, pp. 1517-1519, 2010.

[32] A. Arnida, A. Malugin, and H. Ghandehari, "Cellular uptake and toxicity of gold nanoparticles in prostate cancer cells: a comparative study of rods and spheres," Journal of Applied Toxicology, vol. 30, no. 3, pp. 212-217, 2010.

[33] S. H. Wang, C. W. Lee, A. Chiou, and P. K. Wei, "Sizedependent endocytosis of gold nanoparticles studied by threedimensional mapping of plasmonic scattering images," Journal of Nanobiotechnology, vol. 8, article 33, 2010.

[34] H. Gao, W. Shi, and L. B. Freund, "Mechanics of receptormediated endocytosis," Proceedings of the National Academy of Sciences of the United States of America, vol. 102, no. 27, pp. 9469-9474, 2005.

[35] M. Raoof, Y. Mackeyev, M. A. Cheney, L. J. Wilson, and S. A. Curley, "Internalization of C60 fullerenes into cancer cells with accumulation in the nucleus via the nuclear pore complex," Biomaterials, vol. 33, no. 10, pp. 2952-2960, 2012.

[36] P. di Gianvincenzo, M. Marradi, O. M. Martínez-Avila, L. M. Bedoya, J. Alcamí, and S. Penadés, "Gold nanoparticles capped with sulfate-ended ligands as anti-HIV agents," Bioorganic \& Medicinal Chemistry Letters, vol. 20, no. 9, pp. 2718-2721, 2010.
[37] I. Papp, C. Sieben, A. L. Sisson et al., "Inhibition of influenza virus activity by multivalent glycoarchitectures with matched sizes," ChemBioChem, vol. 12, no. 6, pp. 887-895, 2011.

[38] T. Mustafa, F. Watanabe, W. Monroe et al., "Impact of gold nanoparticle concentration on their cellular uptake by MC3T3E1 mouse osteoblastic cells as analyzed by transmission electron microscopy," Journal of Nanomedicine \& Nanotechnology, vol. 2, pp. 2-7, 2011.

[39] K. Unfried, C. Albrecht, L.-O. Klotz, A. von Mikecz, S. GretherBeck, and R. P. F. Schins, "Cellular responses to nanoparticles: target structures and mechanisms," Nanotoxicology, vol. 1, no. 1, pp. 52-71, 2007. 

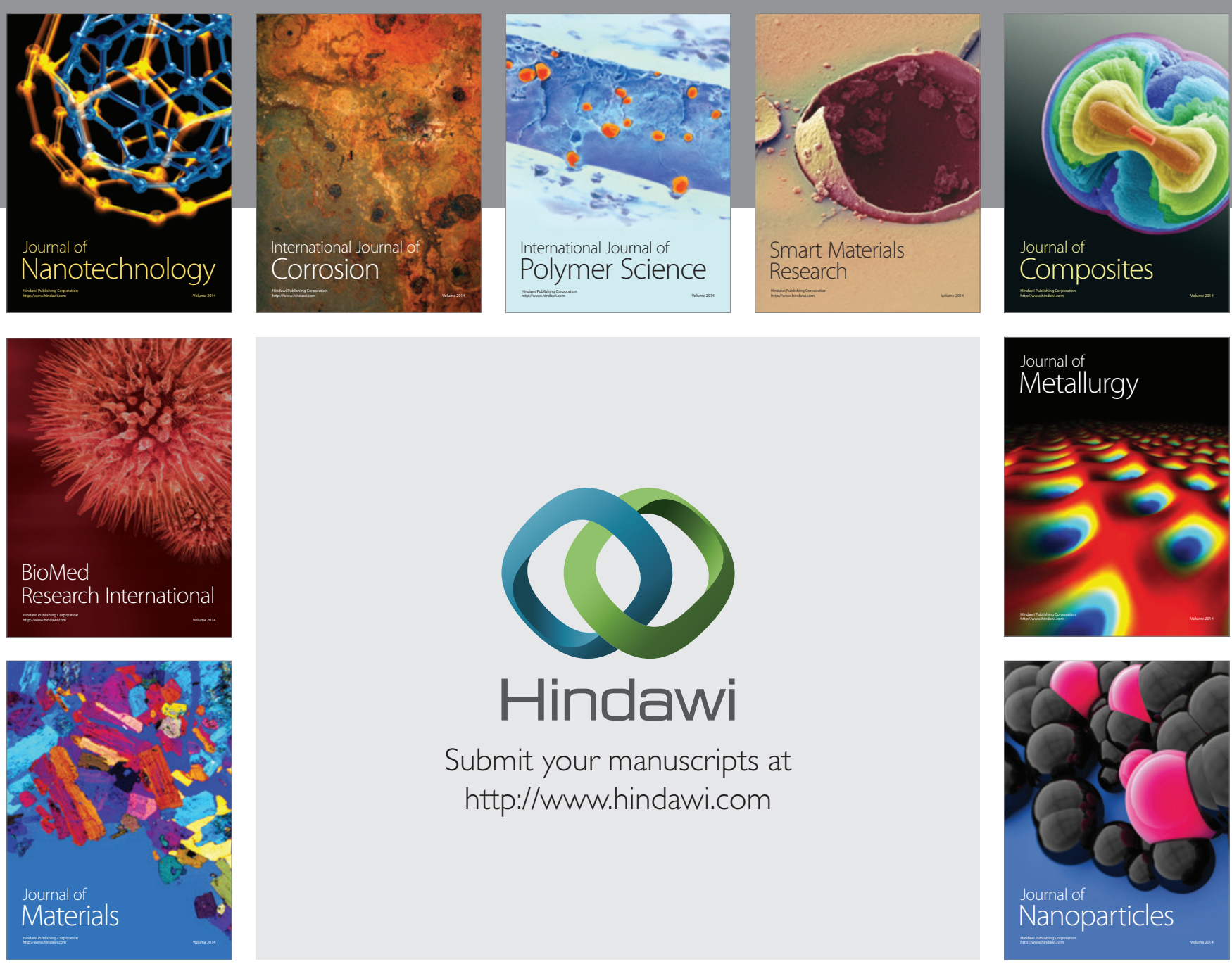

Submit your manuscripts at http://www.hindawi.com
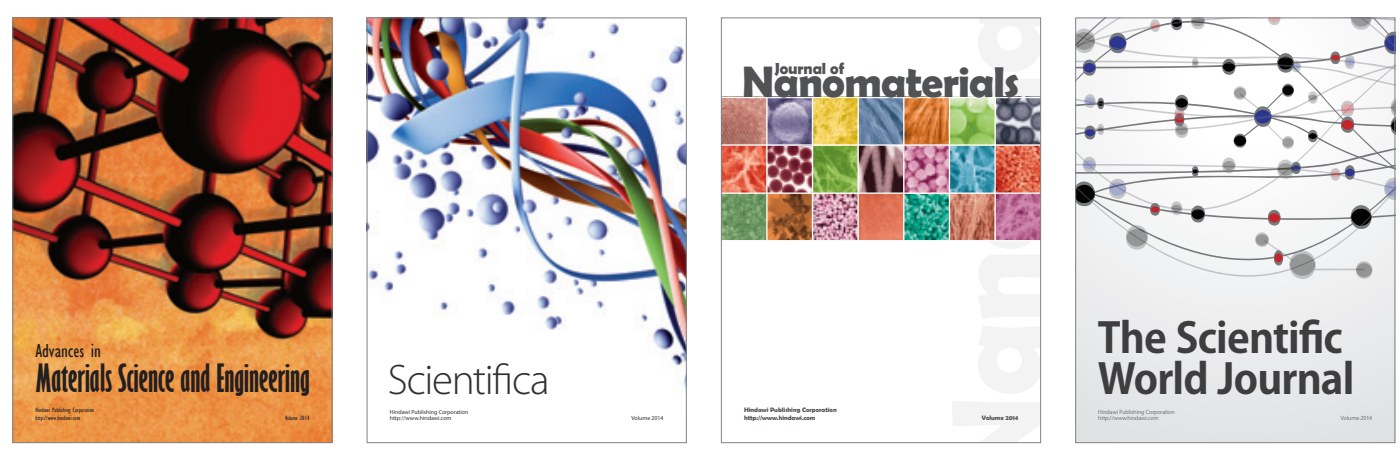

\section{The Scientific World Journal}
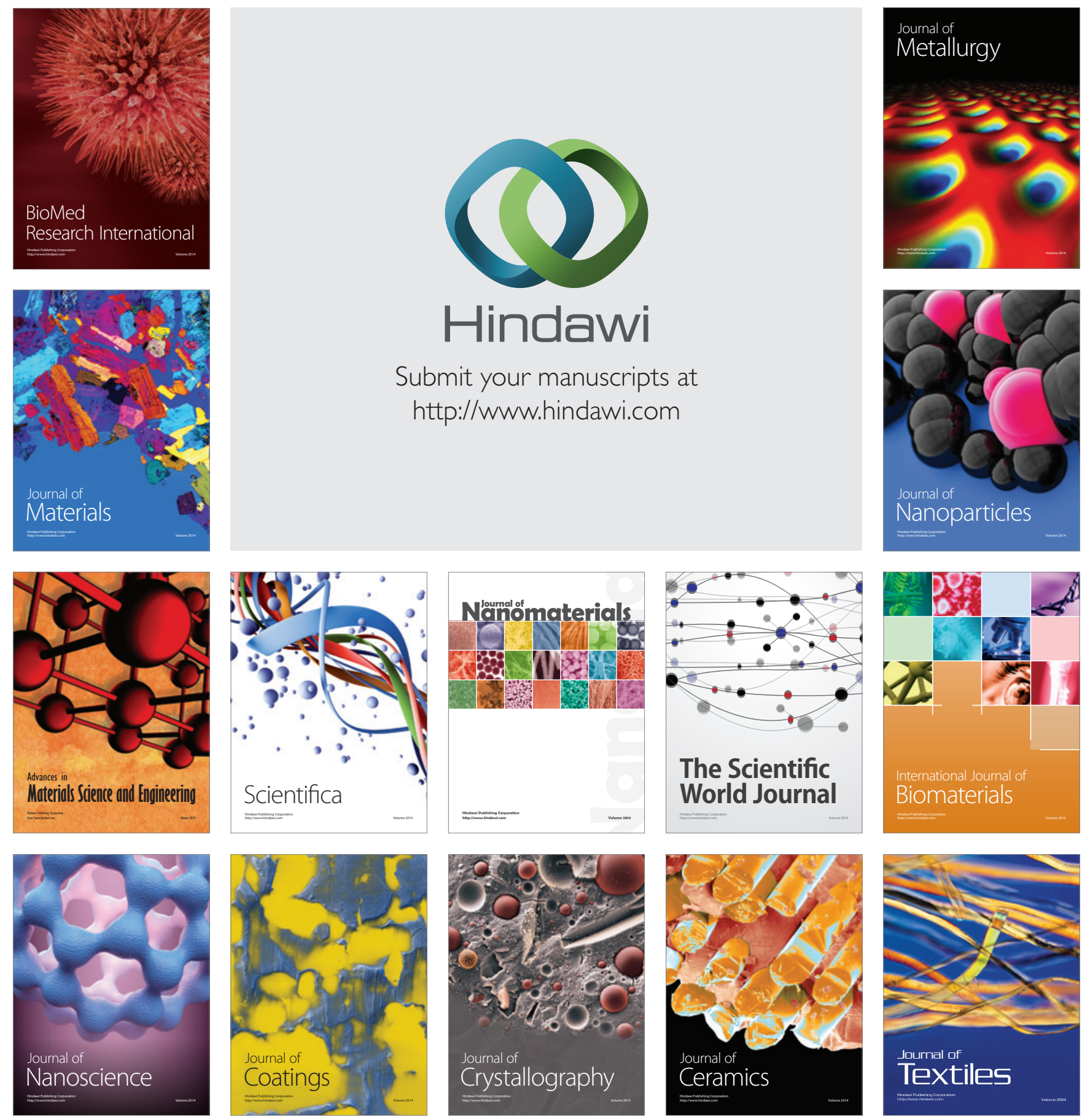